Relations industrielles

Industrial Relations

\title{
Les congés annuels payés édictés par décrets
}

\section{Loi de la convention collective}

\section{Charles Bélanger}

Volume 4, numéro 7, mars 1949

URI : https://id.erudit.org/iderudit/1023503ar

DOI : https://doi.org/10.7202/1023503ar

Aller au sommaire du numéro

\section{Éditeur(s)}

Département des relations industrielles de l’Université Laval

\section{ISSN}

0034-379X (imprimé)

1703-8138 (numérique)

Découvrir la revue

\section{Citer cet article}

Bélanger, C. (1949). Les congés annuels payés édictés par décrets : loi de la convention collective. Relations industrielles / Industrial Relations, 4(7), 66-67. https://doi.org/10.7202/1023503ar

Tous droits réservés @ Département des relations industrielles de l’Université Laval, 1949
Ce document est protégé par la loi sur le droit d'auteur. L’utilisation des services d'Érudit (y compris la reproduction) est assujettie à sa politique d'utilisation que vous pouvez consulter en ligne.

https://apropos.erudit.org/fr/usagers/politique-dutilisation/ 
mule de rapport pour le professeur et la fiche globale de contrôle pour la Commission d'apprentissage.

La fiche globale de contrôle pour la Commission d'apprentissage est un registre cumulatif conçu de façon à ramasser et à coordonner sur une seule formule toutes les informations qui se rapportent à l'apprenti.

Les informations qui constituent la matière de cette fiche sont de divers ordres; elles couvrent les sujets suivants: l'identification, l'arrière-plan scolaire, l'examen médical, l'entrevue, les épreuves psycho-techniques, la formation professionnelle pratique à l'atelier et la formation professionnelle théorique à l'école.

A l'aide de cette somme d'informations réunies de façon concise et pratique, il est alors facile de déterminer rapidement le statut de l'apprenti, de se faire une idée de son profit professionnel et de porter sur sa valeur professionnelle un bon jugement d'ensemble.

\section{Conclusion}

La formation professionnelle dans les métiers d'imprimerie est donc méthodiquement organisée et sera sérieusement contrôlée. L'industrie de l'imprimerie en général, ainsi que les employeurs et les apprentis en particulier, ne pourront que bénéficier du régime de formation professionnelle qu'a élaboré la Commission d'apprentissage.

Il ne faudra pas beaucoup d'années pour qu'avec un pareil régime de formation professionnelle le marché du travail des métiers de l'imprimerie soit réorganisé et qu'à la demande de maind'oeuvre qualifiée réponde une offre adéquate d'ouvriers compétents. En plus de lui fournir les ouvriers qualifiés qui lui font présentement défaut, ce régime de formation professionnelle relèvera le niveau général de la compétence technique de la main-d'oeuvre.

Les employeurs seront de moins en moins contraints à recourir à une main-d'oeuvre semiqualifiée rémunérée aux taux de salaire de la maind'oeuvre qualifiée. Au surplus, le volume comme la qualité de la production croitront. Et ce meilleur rendement de la main-d'oeuvre, cette augmentation ainsi que cette amélioration de la capacité productive de la main-d'oeuvre se traduiront pour les employeurs par une plus grande valeur nette de la production.

Les apprentis acquerront une formation complète dans le métier qu'ils ont choisi. Au terme de leurs six années de formation professionnelle, ils seront en possession d'un précieux capital: un métier maîtrisé dans toutes ses opérations essentielles et non dans quelques-unes de ses opérations seulement. Ce sevoir et cette expérience leur garantiront un emploi continu et un revenu stable en même temps que substantiel. C'est un fait d'expérience quotidienne que la possession d'un métier éprouvé procure un bien-être économique et un niveau de vie supérieurs en même temps que les plus nobles fiertés et la conscience de sa valeur.

Certes, la mise en oeuvre de ce régime de formation professionnelle n'est pas chose facile. Mais que l'Ecole des arts graphiques et les ateliers d'imprimerie assument respectivement les responsabilités qu'elle leur attribue en matière de formation professionnelle, qu'ils s'appliquent en toute loyauté à concourir dans leur propre sphère à la formation professionnelle de ses apprentis et la Commission d'apprentissage, coordonnant les efforts de ces deux foyers complémentaires de formation, atteindra son objectif qui est de doter l'industrie de l'imprimerie d'une main-d'oeuvre plus compétente.

\title{
LES CONGÉS ANNUELS PAYÉS ÉDICTÉS PAR DÉCRETS
}

\author{
Loi de la convention collective
}

Charles Bélanger

La règlementation d'ordre public sur les congés annuels payés dans la province de Québec provient soit des décrets en exécution de la loi de la convention collective, soit de l'ordonnance numéro 3 de la Commission du salaire minimum.

Le Bulletin des relations industrielles a déjà exposé la portée générale et les modalités d'application de l'ordonnance no $3,{ }^{1}$ qui couvre de façon

(1) Bulletin des relations industrielles, Vol. 3, no 10, juin 1948 , p. 149. résiduaire les employés des établissements industriels et commerciaux non régis par les décrets, ou ceux qui ne sont pas assujettis aux conventions collectives de travail prévoyant au moins une semaine de congés annuels payés.

On sait que les décrets s'appliquent à plus de deux cent mille employés d'industries, de commerces et d'occupations diverses en cette province et établissent un régime mieux adapté à leurs conditions du fait que l'on retrouve à la base du 
décret une convention collective de travail." Mais dans quelle mesure les décrets bénéficient-ils aux intéressés et comment concordent-ils avec l'ordonnance no 3 quant aux congés annuels payés ? Nous croyons que l'importance de cette règlementation ne doit pas échapper à tous ceux qui s'intéressent à l'aménagement des relations industrielles. C'est ce que nous tenterons d'exposer brièvement.

A cette fin nous examinerons les décrets en vigueur au 31 décembre 1948 et nous les grouperons selon leur juridiction occupationnelle principale. Nous constatons qu'il y avait à cette date quatre-vingt-seize décrets en vigueur, soit un dans l'industrie minière, trente-six dans les industries manufacturières, quatorze dans la construction, sept dans le transport, dix-sept dans le commerce et vingt-et-un dans les services.

L'examen de ces décrets révèle que soixantedix-sept d'entre eux contiennent des dispositions accordant au moins une semaine de congés annuels payés soit l'équivalent de l'ordonnance no 3. Ils se répartissent comme suit: l'industrie minière: 1 ; les industries manufacturières: 35 ; la construction dont trois pour les employés permanents de l'entretien: 5; le transport: 2; le commerce: 15 et les services 19. Si l'on compare le total de ce groupe au précédent on semble pouvoir conclure que dix-neuf de ces décrets ne comportent pas cet avantage: l'industrie de la boulangerie de Granby; l'industrie de la construction des rigions du Lac St-Jean, de Hull (deux décrets), de Joliette, de St-Hyacinthe, de St-Jean, des cantons de l'Est, de Terrebonne, des Trois-Rivières; le commerce de Sherbrooke et de Magog; les services des barbiers et coiffeurs de Rouyn et de Shesbrooke. Notons cependant que de ce nombre, quatorze décrets concernent des entreprises de caractère saisonnier, soit neuf dans la construction et cinq pour les débardeurs. Remarquons aussi que l'ordonnance numéro 3 n'est pas applicable aux ouvriers occupés à la construction d'immeubles. Ces derniers décrets ne sont donc pas inférieurs sur ce point à l'ordonnance de la Commission du salaire minimum.

(2) Ministère du Travail de la province de Québec. Rapport général du Ministre du Travail, 1948, p. 125.
Par contre, il convient de souligner que vingtdeux décrets dont dix dans les industries marufacturières, un dans le transport, sept dans le commerce et quatre dans les services donnent deux semaines de congés payés et que de plus un décret dans l'industrie minière accorde trois semaines aux employés assujettis. Les travailleurs couverts par ces vingt-trois décrets bénéficient donc de congés beaucoup plus généreux que ceux de toute autre règlementation.

Toutefois, on se doit d'observer que malgré leur tendance générale à établir un régime plus favorable, quarante-huit n'accordent qu'une semaine de congés annuels payés sans imposer aux employeurs l'obligation de faire bénéficier leurs employés, lors de la résiliation de leur contrat de travail, d'une indemnité compensatrice pour les vacances accumulées, ainsi que le stipule l'ordonnance numéro 3 pour les employés soumis à sa juridiction.

Bien plus, de ce nombre nous relevons dix décrets permettant une compensation du double du salaire pour tenir lieu de congés payés. On ne peut donc interpréter une telle disposition comme garantissant des congés payés. Il s'agit ici d'une prime au travail plutôt que d'un droit aux congés annuels payés.

Malgré les imperfections qu'on retrouve dans cette règlementation, il $\mathrm{y}$ a lieu d'observer que la situation actuelle marque un très grand progrès, surtout si on la compare avec l'année 1940 alors que quatre décrets seulement imposaient des congés annuels payés. Sept ans après, soit en 1947, soixante-et-un décrets comportent de telles conditions; c'est un gain appréciable de seize nouvelles mesures règlementaires pour l'année 1948, sans compter que certains décrets sont venus ajouter aux avantages déjà consentis.

Remarquons également, pour conclure cette brève analyse, que parmi les établissements visés par les décrets un très grand nombre appliqucnt une politique de beaucoup plus avantageuse que le régime légal, allant jusqu'à quatre semaines de congés annuels payés ou faisant bénéficier les travailleurs d'un taux croissant de rémunération pour leurs congés annuels. 